\title{
Evidence for the benefit of exercise therapy in patients with type 2 diabetes
}

This article was published in the following Dove Press journal:

Diabetes, Metabolic Syndrome and Obesity:Targets and Therapy 2 July 2013

Number of times this article has been viewed

\section{Kenneth M Madden \\ VITALiTY (Vancouver Initiative to Add Life to Years) Research Laboratory, Division of Geriatric Medicine, Department of Medicine, University of British Columbia, Vancouver, BC, Canada}

\begin{abstract}
Exercise interventions are recommended in most guidelines for the treatment of type 2 diabetes. Although most guidelines suggest a combination of both aerobic and resistance training, the exact benefits of these interventions remain unclear. Although either modality alone or in combination seems to have an identical impact on glycated hemoglobin levels, resistance training and aerobic training have independent effects on other parameters of cardio-metabolic risk. This review examines the current evidence for aerobic and resistance training on glycemic control, lipid profile, body composition, vascular health, and mental health in patients with type 2 diabetes. The uncertainties surrounding exercise modality, volume and intensity are also addressed.
\end{abstract}

Keywords: aerobic exercise, resistance exercise, glycemic control, cardio-metabolic risk

\section{Introduction}

The prevalence of diabetes has currently reached epidemic proportions, and is a leading global source of mortality and morbidity. ${ }^{1}$ Despite a proliferation of new treatment modalities, the expense of treating diabetes is expected to double over the next 25 years. ${ }^{2}$ Traditionally, the three cornerstones of therapy for type 2 diabetes have consisted of medications, diet interventions, and exercise. Regular exercise training has been advocated as part of numerous practice guidelines, including the American Diabetes Association, ${ }^{3,4}$ the American College of Sports Medicine, ${ }^{5,6}$ the American Heart Association, ${ }^{7}$ and the Canadian Diabetes Association. ${ }^{8,9}$ Despite the implied certainty of these guidelines, there is much debate among investigators over the volume, intensity, and type of exercise that will most benefit this vulnerable population. Due to the complexity and expense involved in randomized controlled trials of exercise, much of the literature is muddled by small subject size and heterogeneity of training intensity, volume, and frequency. Some recent meta-analyses of exercise interventions in patients with type 2 diabetes have helped to clarify some of these issues, but the ideal exercise type and intensity needs to be determined.

\section{Types of exercise}

"Exercise" is any "planned or structured physical activity" performed to improve one of the components of physical fitness. ${ }^{10}$ Although there are many different types of exercise, there are only two that have been extensively examined in the setting of type 2 diabetes: endurance training and resistance training. "Endurance training" is defined as any exercise designed to increase cardiovascular fitness, often defined as an increase in the maximal uptake of oxygen. "Resistance training" is defined as any

\footnotetext{
Correspondence: Kenneth M Madde University of British Columbia, Room 7185, Gordon and Leslie Diamond Health Care Centre, 2775 Laurel St, Vancouver, BC, Canada, V5Z IM9

$\mathrm{Tel}+$ I 604875493 I

Fax + I 6048755696

Email kenneth.madden@ubc.ca
}

submit your manuscript $\mid$ www.dovepress.com

Dovepress

http://dx.doi.org// 0.2147/DMSO.S3295 
exercise designed to improve the strength and size of skeletal musculature. ${ }^{11}$ The efficacy of endurance training, resistance training, and combination training in patients with type 2 diabetes has been examined to various degrees with respect to glycemic control, lipid profile, body composition, quality of life, and peripheral vascular health.

\section{Exercise and glycemic control}

The main measure of glycemic control is glycosylated hemoglobin $\left(\mathrm{Hb}_{\mathrm{Alc}}\right)$, which gives an overall indication of glycemic control over the previous 12 weeks. ${ }^{9}$ It is postulated that aerobic exercise improves glycemic control in type 2 diabetes primarily through increasing insulin sensitivity. ${ }^{12}$ A small study utilizing hyperinsulinemic euglycemic clamps has demonstrated an improvement in insulin sensitivity with only 15 days of aerobic exercise. ${ }^{13}$ A recent metaanalysis by Umpierre et al combined the results of 23 studies with 1533 subjects and demonstrated that a structured aerobic training intervention improved $\mathrm{Hb}_{\mathrm{Alc}}$ by $0.73 \%$ $(0.40 \%-1.06 \%){ }^{14}$ The studies all had a training frequency of 2-5 times per week for 30-90 minutes per session over interventions of 12-52 weeks. Overall, it is well established that aerobic exercise improves glycemic control to a moderate extent. By comparison, oral hypoglycemic medications have been shown to reduce glycosylated hemoglobin from $0.5 \%$ to $2.0 \% .^{15}$

Resistance training has also been considered to improve glycemic control, although it is not as well studied as aerobic training. It is postulated that resistance training improves glycemic control by a different mechanism than aerobic training, mainly through an increase in muscle mass (since skeletal muscle is the main glucose sink for the body) and by increasing glucose transporter type 4 (GLUT-4) expression. ${ }^{12}$ An increase in GLUT-4 expression has been supported by inactivity studies involving muscle biopsies in human subjects ${ }^{16}$ and in exercise interventions in rats. ${ }^{17} \mathrm{~A}$ meta-analysis of the effects of resistance training by Umpierre et $\mathrm{al}^{14}$ involving four studies and a total of 261 subjects demonstrated an improvement in $\mathrm{Hb}_{\mathrm{Alc}}$ of $0.57 \%$ $(0.01 \%-1.14 \%)$. The frequency of workouts was three times per week and the interventions lasted between 16 and 39 weeks. Overall, resistance training is well established as a treatment to improve glycemic control in type 2 diabetes.

\section{Exercise and the lipid profile in type 2 diabetes}

The impact of aerobic and resistance exercise interventions on the lipid profile of persons with type 2 diabetes has been difficult to determine, due to numerous small, conflicting studies. A meta-analysis examining the effects of aerobic training on lipid profile was performed by Kelley et al, who found a total of four studies comprising only 220 subjects. Endurance training was found to result in a 5\% decrease in low-density lipoprotein cholesterol (LDL-C), but had no impact on high-density lipoprotein cholesterol (HDL-C), total cholesterol, or triglycerides. ${ }^{18}$ Two other meta-analyses attempted to examine the effects of both aerobic and resistance training on lipid parameters in type 2 diabetes, but found either no impact ${ }^{19}$ or clinically insignificant improvements ${ }^{12,20}$ in HDL-C levels. However, neither of these meta-analyses assessed the risk of bias, which might explain their negative findings. Recently, a more sophisticated meta-analysis by Hayashino et al addressed both bias and study heterogeneity. ${ }^{21}$ This study found HDL-C ( $\mathrm{n}=35$ studies; 2059 patients) was increased by $0.04 \mathrm{mmol} / \mathrm{L}$, and LDL-C ( $\mathrm{n}=25$ studies; 1807 patients) was decreased by $0.16 \mathrm{mmol} / \mathrm{L}$. Although this impact on low-density lipoprotein is less than that seen with either statin use or diet intervention, it does suggest that exercise is a valuable adjuvant treatment for dyslipidemias in patients with type 2 diabetes. ${ }^{21}$

The results of the meta-analysis done by Hayashino et al are supported by the results of the 4-year Look AHEAD (Action for Health in Diabetes) trial, which was a multicenter randomized trial of an intensive lifestyle intervention on cardiovascular risk in subjects with type 2 diabetes. ${ }^{22,23}$ The studied intervention included both dietary and physical fitness (primarily aerobic exercise of a similar intensity to brisk walking) interventions. The program demonstrated improvements in both HDL-C, LDL-C, and total cholesterol levels, although it is difficult to distinguish how much of the improvements were due solely to the exercise component of the intervention. ${ }^{22,23}$

Overall, more work needs to be done to determine the appropriate type, intensity, and volume of exercise required to improve the lipid profile in type 2 diabetes.

\section{Exercise and body composition}

Diabetes appears to have an effect on both lean body mass and muscle quality, perhaps due to poor vascular supply and peripheral neuropathy. ${ }^{24}$ The effects of different types of exercise interventions on body composition remain uncertain, as most of the numerous studies have been small. An 8-week aerobic exercise intervention demonstrated no impact on body mass index in either Caucasian or African-American subjects but resistance training showed a decrease in body mass index in African-Americans only. ${ }^{25}$ Neither intervention in this study 
had any impact on waist-to-hip ratio, or body fat percentage. ${ }^{25}$ Contrary to these results, a much larger randomized controlled study demonstrated that resistance training for 16 weeks (three times per week) reduced visceral fat as well as increasing fat-free mass. ${ }^{26}$ A combination diet and light-to-moderate aerobic exercise intervention in patients with type 2 diabetes enrolled in the Look AHEAD trial demonstrated a decrease in fat mass and an improvement in fat distribution after 1 year of the intervention, although the improvements in fat mass and fat distribution were more profound in male than in female subjects. ${ }^{27}$ Similarly, a combination high-protein diet and resistance training intervention in adults with type 2 diabetes also showed improvements in body composition (as measured by fat mass and waist circumference). ${ }^{28}$

A meta-analysis by Hayashino et al demonstrated that structured exercise interventions generally resulted in improvements to both waist circumference and body mass index. However, when the different types of exercise were examined separately, significant improvements in body mass index and waist circumference were only seen with aerobic and combination (aerobic plus resistance) exercise interventions. ${ }^{21}$ Overall, there appears to be the most evidence for the benefits of exercise on body composition if the intervention is mixed (aerobic plus resistance training) and if the intervention is combined with other lifestyle interventions such as dietary improvements.

\section{Exercise and mental health}

One neglected impact of diabetes on patients is impaired emotional well-being and an increased risk of depression. ${ }^{29}$ Physical activity is often recommended as a potential intervention to improve quality of life, prevent depression, reduce anxiety, and increase overall emotional well-being, and there is some evidence for these benefits in healthy, normal populations. ${ }^{30}$ There is also evidence for benefits in patients with type 2 diabetes, although due to the nature of the outcomes measured, the studies are quite heterogeneous. ${ }^{31}$ A recent meta-analysis by Ligtenberg et al demonstrated that aerobic training reduced anxiety measures in subjects with type 2 diabetes, although there was no impact on quality-oflife scores. ${ }^{32} \mathrm{~A}$ 4-month resistance training intervention in 58 subjects with type 2 diabetes demonstrated an improvement in various depression scores, although an aggregate metaanalysis of the contemporary literature showed no benefits on quality-of-life scores with resistance training. ${ }^{33}$ Although the impact on overall quality of life remains uncertain, clearly both aerobic and resistance training can have an impact on the symptoms of depression in patients with type 2 diabetes.

\section{Exercise and vascular stiffness}

Type 2 diabetes has been shown to accelerate the increase in vascular stiffening ${ }^{34}$ that occurs during the normal aging process. ${ }^{35}$ The relationship between reduced arterial compliance and cardiovascular mortality is well established. ${ }^{36}$ Prospective examinations of a moderate aerobic exercise program in middle-aged subjects with type 2 diabetes ${ }^{37}$ have demonstrated a decrease in arterial stiffness. It has been hypothesized that mechanical distension during aerobic exercise sessions results in pulsatile "stretching" of the collagen fibers that reverses the glycation-related collagen cross-linking that is responsible for reduced arterial compliance in diabetes. ${ }^{38} \mathrm{~A}$ short-term (12-week) aerobic exercise intervention in older adults with extensive vascular damage due to multiple etiologies (type 2 diabetes, hypercholesterolemia, hypertension) demonstrated quite a large decrease in arterial stiffness, without any corresponding improvements in glycemic control, blood pressure, lipid profile, or body composition measures. ${ }^{39}$ This suggests that there may be mortality benefits to exercise in the setting of type 2 diabetes, even in the absence of any improvement in glycemic control. Light strength training (the active control arm in the study) seemed to have a neutral impact on arterial stiffness, ${ }^{39}$ although this is still under-investigated.

\section{Volume and intensity of exercise required}

A recent meta-analysis by Umpierre et al demonstrated that a weekly exercise volume $>150$ minutes per week resulted in an absolute $\mathrm{Hb}_{\mathrm{Alc}}$ reduction of $0.89 \%$ while an exercise intervention $<150$ minutes per week only reduced $\mathrm{Hb}_{\mathrm{Alc}}$ by $0.36 \%$. This was regardless of the type of exercise undertaken, but the majority of the studies in this metaanalysis consisted of aerobic training (since resistance exercise tended to be reported as number of repetitions rather than duration).${ }^{14}$ However, another study has suggested that exercise intensity tends to have a larger impact on insulin sensitivity, while training volume tends to have more of an impact on $\mathrm{Hb}_{\mathrm{Alc}}{ }^{40}$

Although more work needs to be done to resolve this issue, it appears that the current American Diabetes Association recommendation of more than 150 minutes per week is sound. The role of high-intensity exercise in type 2 diabetes needs further examination, finding a balance between the more recently examined benefits of highintensity interval training and the potential risks of injury in a sedentary population. ${ }^{41}$ 


\section{Exercise type}

Which type of exercise is better in type 2 diabetes? From a strict glycemic control perspective (specifically the impact on glycated hemoglobin levels), there does not seem to be much difference in benefit. A recent meta-analysis demonstrated similar benefits from endurance training, strength training, and combination training when compared with controls. There did not seem to be any overall benefit of one training modality over another, in terms of glycemic control, with each modality reducing $\mathrm{Hb}_{\mathrm{Alc}}$ by approximately $0.5 \% .{ }^{14}$ This means that the modality of exercise chosen to improve glycemic control can be matched according to the comorbidities of the patient. In addition, strength training was done less often (approximately 2-3 times per week), so this might be an easier intervention to implement in a sedentary population.

Of course, there are well-documented synergistic benefits to combining both aerobic and strength training that are independent of any impact on glycemic control. Resistance training has well-documented benefits in terms of muscle mass, muscle strength, and level of function, while aerobic training has an independent impact on cardiovascular endurance. ${ }^{42}$ This suggests that a combination regime might be the best overall intervention in type 2 diabetes, if one considers issues other than just glycemic control. In addition, the fact that strength training provided similar glycemic benefits with a lower training frequency per week suggests that if the two modalities are combined, they should not occur together on the same day of the week, so as to maximize any synergistic effects. ${ }^{14}$

\section{High-intensity training}

Although the benefits of exercise in type 2 diabetes are well established, targets for physical activity are not being met in the majority of the population. The reduction in physical activity is felt to be one of the main reasons for the increasing prevalence of both obesity and the many cardio-metabolic complications of this condition (including diabetes). ${ }^{43}$ The main barrier to physical activity cited by all patients, regardless of ethnicity, comorbidities, age, or sex is a perceived "lack of time." Adherence to standard exercise prescriptions involving prolonged submaximal aerobic exertion has been shown to be extremely poor. ${ }^{43}$ This inability of the medical establishment to translate current physical activity guidelines into changes in patient behavior has sparked interest into the role of low-volume (and therefore low time commitment), but high-intensity exercise interventions. The most commonly examined high-intensity intervention is high-intensity interval training (HIT).
High-volume HIT has a well-established ability to increase cardiorespiratory fitness to a greater extent than conventional endurance training in normal adults. ${ }^{44}$ However, these findings are not particularly useful in addressing the barriers to physical activity in the type 2 diabetes population, since high-volume HIT interventions have approximately the same time commitment as standard aerobic training.

Although there is an underlying biological rationale for HIT, ${ }^{45,46}$ whether low-volume (and therefore short time commitment) HIT can provide similar benefits to the type 2 diabetes population remains to be determined. Unfortunately, the study of low-volume HIT in patients with type 2 diabetes is quite limited. One study by Gillen et al examined effects of a single dose of low-volume HIT $(10 \times 60$ seconds cycling at $90 \%$ maximal heart rate) on continuous glucose monitoring. ${ }^{47}$ They successfully showed that a single dose of low-volume HIT significantly reduced hyperglycemia over a 24-hour period and also significantly reduced postprandial hyperglycemia. Significantly, these improvements occurred despite the time commitment being well below the current suggested guideline of 150 minutes per week. ${ }^{47}$ Although all these results are suggestive of a future role for low-volume HIT in the treatment of type 2 diabetes, much more work needs to be done to further examine the risks and benefits of such a treatment.

\section{Exercise, diabetes, and ethnicity}

Several investigations have looked into the efficacy of exercise interventions as treatment for type 2 diabetes in different high-risk populations. A recent meta-analysis ${ }^{48}$ found nine trials that examined the effects of resistance and aerobic training in various ethnic populations. The greatest reduction in $\mathrm{Hb}_{\mathrm{Alc}}$ with either resistance or endurance training was found in Indian and Latino populations, as long as the training intervention period was greater than 16 weeks. Interestingly, one trial demonstrated that a short-term (only 12 weeks) combined training intervention reduced glycated hemoglobin in Caucasian subjects but not in Arabian subjects. ${ }^{49}$ Various other trials did not show any effect of aerobic training versus control groups in either AfricanAmerican, Chinese, or Polynesian subject populations. ${ }^{48}$ Thus, although much more work needs to be done, there is some indication that the effects of exercise training might have different levels of efficacy on $\mathrm{Hb}_{\mathrm{Alc}}$ levels in different patient populations.

Similarly, exercise appears to have different effects on body composition in populations of different ethnicities. Resistance training appears to have a greater impact on anthropomorphic measures in an African-American population than 
in a Caucasian population. ${ }^{26}$ Neither aerobic nor resistance training seemed to have any impact on body composition (waist circumference or body fat percentage) in obese MiddleEastern and Polynesian subjects. ${ }^{49,50}$ A larger study of older Latino subjects, however, demonstrated an increase in whole body fat-free mass with resistance training, as measured by dual-energy X-ray absorptiometry. ${ }^{51}$ Thus, as with glycemic control, the body compositions of different patient populations may respond to exercise interventions differently.

\section{Exercise and metabolic syndrome}

Although "metabolic syndrome" has numerous definitions, it is generally defined as a clustering of cardio-metabolic risk factors associated with insulin resistance. Metabolic syndrome has been shown to greatly increase the risk of type 2 diabetes. ${ }^{52}$ The cardio-metabolic risk factors consist of increased central obesity (waist circumference), increased blood pressure, increased triglycerides, decreased HDL-C, and increased fasting plasma glucose. ${ }^{53}$ The more time spent being sedentary has been definitively shown to increase the risk of meeting the criteria for metabolic syndrome, supporting the use of exercise interventions to treat this condition. ${ }^{54}$ Data from the Finnish Diabetes Prevention Study have also shown that increased time spent in physical activity during leisure time was predictive of a greater likelihood of prevention and resolution of metabolic syndrome (even after correcting for weight loss and changes in dietary intake). ${ }^{55}$

A randomized controlled trial by McAuley et al of an intensive aerobic exercise and dietary intervention in 79 insulin-resistant subjects demonstrated significant improvements in insulin sensitivity when compared with the control group (which received standard dietary and physical activity advice). Given that the only difference between the two groups was increased aerobic capacity in the intervention arm, the study suggests that aerobic training is an effective intervention to improve insulin sensitivity. ${ }^{56}$ Likewise, a metaanalysis by Strasser et al examining the impact of resistance training in subjects with obesity-related glucose intolerance demonstrated a positive impact on some of the components that cluster together in metabolic syndrome $\left(\mathrm{Hb}_{\mathrm{Alc}}\right.$, blood pressure, and central adiposity). ${ }^{57}$

Although numerous studies have shown the benefits of both aerobic and resistance training on each individual component of metabolic syndrome, there have been very few prospective, randomized controlled trials of either aerobic or resistance training in the prevention of metabolic syndrome. Aerobic training in 621 subjects with metabolic syndrome resulted in approximately $30 \%$ of subjects no longer having the condition after 20 weeks, ${ }^{58}$ with the largest improvements seen in serum triglycerides and blood pressure. Another prospective study by Jurca et al (with a mean follow-up time of about 7 years) demonstrated that measures of muscular strength in 3233 male subjects free of metabolic syndrome were inversely related to the risks of developing this condition. ${ }^{59}$ Although the exact amount of aerobic and resistance training still needs to be determined, clearly some combination of these two interventions has a role to play in the treatment of metabolic syndrome.

\section{Conclusion and future directions}

Although there are clear benefits of training in terms of glycemic control, lipid profile, body composition, quality of life, and vascular health, much uncertainty remains as to the ideal exercise prescription for adults with type 2 diabetes. Further study needs to be done to determine what the "minimum effective dose" is for each of the various exercise interventions, and how best to combine them. Certainly, the current recommendation of more than 150 minutes of training (regardless of modality) per week appears to be valid, and should be implemented for all patients. The glycemic benefits of exercise training appear to be modest (an approximate decline in $\mathrm{Hb}_{\mathrm{Alc}}$ of $0.5 \%$ ), which suggests that exercise cannot be a sole intervention but should be an adjunctive to both medication and dietary interventions. Moreover, much more work needs to be done on the mental health benefits of training in the setting of type 2 diabetes, as well as how populations with different ethnicities respond to training.

\section{Clinical recommendations}

- When exercise is prescribed in the setting of type 2 diabetes, the volume of exercise should be greater than 150 minutes per week.

- Although it makes no difference for glycemic control, the other non-overlapping benefits of resistance and endurance training suggest that a combination approach (with different modalities on different days of the week) is the best approach.

- Since there is no evidence currently for an ideal ratio of resistance to aerobic training, this should be determined according to the patient's comorbidities such as musculoskeletal issues or coronary artery disease.

- Although a greater intensity of exercise seems to have a greater impact on insulin sensitivity, this benefit needs to be weighed against the greater risk of injury with high-intensity interventions. In the absence of more definitive studies, patients should undertake the highest intensity exercise possible that is both safe and tolerable. 
- We still do not understand the impact of ethnicity on the effectiveness of exercise in diabetes. Different populations may respond differently to different interventions, but there is not yet enough evidence to support different exercise prescriptions in different populations.

- The role of low-volume, HIT still needs to be established in type 2 diabetes. This could be considered as a potential exercise prescription if the patient's comorbidities allow for such a high-intensity intervention. It should be especially considered as an alternative if compliance with standard exercise prescriptions is poor due to perceived time constraints on the part of the patient.

- Exercise prescriptions are not a primary therapy for type 2 diabetes. Endurance and resistance training should be considered adjunctive therapy in addition to dietary modifications and hypoglycemic agents.

\section{Disclosure}

The author declares no conflicts of interest in this work.

\section{References}

1. Danaei G, Finucane MM, Lu Y, et al; Global Burden of Metabolic Risk Factors of Chronic Diseases Collaborating Group (Blood Glucose). National, regional, and global trends in fasting plasma glucose and diabetes prevalence since 1980: systematic analysis of health examination surveys and epidemiological studies with 370 country-years and 2.7 million participants. Lancet. 2011;378(9785): $31-40$.

2. Huang ES, Basu A, O'Grady M, Capretta JC. Projecting the future diabetes population size and related costs for the US. Diabetes Care. 2009;32(12):2225-2229.

3. American Diabetes Association. Standards of medical care in diabetes - 2013. Diabetes Care. 2013;36 Suppl 1:S11-S66.

4. American College of Sports Medicine and American Diabetes Association joint position statement. Diabetes mellitus and exercise. Med Sci Sports Exerc. 1997;29(12):i-vi.

5. Colberg SR, Sigal RJ, Fernhall B, et al; American College of Sports Medicine; American Diabetes Association. Exercise and type 2 diabetes: the American College of Sports Medicine and the American Diabetes Association: joint position statement executive summary. Diabetes Care. 2010;33(12):2692-2696.

6. Albright A, Franz M, Hornsby G, et al. American College of Sports Medicine position stand. Exercise and type 2 diabetes. Med Sci Sports Exerc. 2000;32(7):1345-1360.

7. Marwick TH, Hordern MD, Miller T, et al; Council on Clinical Cardiology, American Heart Association Exercise, Cardiac Rehabilitation, and Prevention Committee; Council on Cardiovascular Disease in the Young; Council on Cardiovascular Nursing; Council on Nutrition, Physical Activity, and Metabolism; Interdisciplinary Council on Quality of Care and Outcomes Research. Exercise training for type 2 diabetes mellitus: impact on cardiovascular risk: a scientific statement from the American Heart Association. Circulation. 2009;119(25):3244-3262.

8. Canadian Diabetes Association. Canadian Diabetes Association 2013 Clinical Practice Guidelines for the Prevention and Management of Diabetes in Canada. Canadian Journal of Diabetes. 2013;37(S1):A1-A16, S1-S216.

9. Bhattacharyya OK, Estey EA, Cheng AY. Update on the Canadian Diabetes Association 2008 clinical practice guidelines. Can Fam Physician. 2009;55(1):39-43.
10. Zanuso S, Jimenez A, Pugliese G, Corigliano G, Balducci S. Exercise for the management of type 2 diabetes: a review of the evidence. Acta Diabetol. 2010;47(1):15-22.

11. Schwellnus M, editor. The Olympic Textbook of Medicine in Sport. Oxford, UK and Hoboken, NJ: Wiley-Blackwell; 2008.

12. Snowling NJ, Hopkins WG. Effects of different modes of exercise training on glucose control and risk factors for complications in type 2 diabetic patients: a meta-analysis. Diabetes Care. 2006;29(11):2518-2527.

13. Winnick JJ, Sherman WM, Habash DL, et al. Short-term aerobic exercise training in obese humans with type 2 diabetes mellitus improves whole-body insulin sensitivity through gains in peripheral, not hepatic insulin sensitivity. J Clin Endocrinol Metab. 2008;93(3):771-778.

14. Umpierre D, Ribeiro PA, Kramer CK, et al. Physical activity advice only or structured exercise training and association with $\mathrm{HbA} 1 \mathrm{c}$ levels in type 2 diabetes: a systematic review and meta-analysis. JAMA. 2011;305(17):1790-1799.

15. Willett LL, Albright ES. Achieving glycemic control in type 2 diabetes: a practical guide for clinicians on oral hypoglycemics. South Med J. 2004;97(11):1088-1092.

16. Tabata I, Suzuki Y, Fukunaga T, Yokozeki T, Akima H, Funato K. Resistance training affects GLUT- 4 content in skeletal muscle of humans after 19 days of head-down bed rest. J Appl Physiol. 1999;86(3): 909-914.

17. Etgen GJ Jr, Jensen J, Wilson CM, Hunt DG, Cushman SW, Ivy JL. Exercise training reverses insulin resistance in muscle by enhanced recruitment of GLUT-4 to the cell surface. Am J Physiol. 1997; 272(5 Pt 1):E864-E869.

18. Kelley GA, Kelley KS. Effects of aerobic exercise on lipids and lipoproteins in adults with type 2 diabetes: a meta-analysis of randomizedcontrolled trials. Public Health. 2007;121(9):643-655.

19. Chudyk A, Petrella RJ. Effects of exercise on cardiovascular risk factors in type 2 diabetes: a meta-analysis. Diabetes Care. 2011;34(5):1228-1237.

20. Honkola A, Forsen T, Eriksson J. Resistance training improves the metabolic profile in individuals with type 2 diabetes. Acta Diabetol. 1997;34(4):245-248.

21. Hayashino Y, Jackson JL, Fukumori N, Nakamura F, Fukuhara S. Effects of supervised exercise on lipid profiles and blood pressure control in people with type 2 diabetes mellitus: a meta-analysis of randomized controlled trials. Diabetes Res Clin Pract. 2012;98(3):349-360.

22. Pi-Sunyer X, Blackburn G, Brancati FL, et al. Reduction in weight and cardiovascular disease risk factors in individuals with type 2 diabetes: one-year results of the look AHEAD trial. Diabetes Care. 2007;30(6): 1374-1383.

23. Wing RR. Long-term effects of a lifestyle intervention on weight and cardiovascular risk factors in individuals with type 2 diabetes mellitus: four-year results of the Look AHEAD trial. Arch Intern Med. 27, 2010; 170(17):1566-1575.

24. Inaba M, Kurajoh M, Okuno S, et al. Poor muscle quality rather than reduced lean body mass is responsible for the lower serum creatinine level in hemodialysis patients with diabetes mellitus. Clin Nephrol. 2010;74(4):266-272.

25. Winnick JJ, Gaillard T, Schuster DP. Resistance training differentially affects weight loss and glucose metabolism of White and African American patients with type 2 diabetes mellitus. Ethn Dis. 2008;18(2): $152-156$.

26. Wycherley TP, Noakes M, Clifton PM, Cleanthous X, Keogh JB, Brinkworth GD. A high-protein diet with resistance exercise training improves weight loss and body composition in overweight and obese patients with type 2 diabetes. Diabetes Care. 2010;33(5):969-976.

27. Albu JB, Heilbronn LK, Kelley DE, et al. Metabolic changes following a 1-year diet and exercise intervention in patients with type 2 diabetes. Diabetes. 2010;59(3):627-633.

28. Wycherley TP, Noakes M, Clifton PM, Cleanthous X, Keogh JB, Brinkworth GD. A high-protein diet with resistance exercise training improves weight loss and body composition in overweight and obese patients with type 2 diabetes. Diabetes Care. 2010;33(5):969-976. 
29. Ali S, Stone MA, Peters JL, Davies MJ, Khunti K. The prevalence of co-morbid depression in adults with Type 2 diabetes: a systematic review and meta-analysis. Diabet Med. 2006;23(11):1165-1173.

30. Gillison FB, Skevington SM, Sato A, Standage M, Evangelidou S. The effects of exercise interventions on quality of life in clinical and healthy populations; a meta-analysis. Soc Sci Med. 2009;68(9):1700-1710.

31. van der Heijden MM, van Dooren FE, Pop VJ, Pouwer F. Effects of exercise training on quality of life, symptoms of depression, symptoms of anxiety and emotional well-being in type 2 diabetes mellitus: a systematic review. Diabetologia. 2013;56(6):1210-1225.

32. Ligtenberg PC, Godaert GL, Hillenaar EF, Hoekstra JB. Influence of a physical training program on psychological well-being in elderly type 2 diabetes patients. Psychological well-being, physical training, and type 2 diabetes. Diabetes Care. 1998;21(12):2196-2197.

33. Lincoln AK, Shepherd A, Johnson PL, Castaneda-Sceppa C. The impact of resistance exercise training on the mental health of older Puerto Rican adults with type 2 diabetes. J Gerontol B Psychol Sci Soc Sci. 2011;66(5):567-570

34. Tedesco MA, Natale F, Di Salvo G, Caputo S, Capasso M, Calabró R. Effects of coexisting hypertension and type II diabetes mellitus on arterial stiffness. J Hum Hypertens. 2004;18(7):469-473.

35. Mitchell GF, Parise H, Benjamin EJ, et al. Changes in arterial stiffness and wave reflection with advancing age in healthy men and women the Framingham Heart Study. Hypertension. 2004;43(6):1239-1245.

36. Benetos A. Pulse pressure and arterial stiffness in type 1 diabetic patients. J Hypertens. 2003;21(11):2005-2007.

37. Yokoyama H, Emoto M, Fujiwara S, et al. Short-term aerobic exercise improves arterial stiffness in type 2 diabetes. Diabetes Res Clin Pract 2004;65(2):85-93

38. Cencetti S, Lagi A, Cipriani M, Fattorini L, Bandinelli G, Bernardi L. Autonomic control of the cerebral circulation during normal and impaired peripheral circulatory control. Heart. 1999;82(3):365-372.

39. Madden KM, Lockhart C, Cuff D, Potter TF, Meneilly GS. Short-term aerobic exercise reduces arterial stiffness in older adults with type 2 diabetes, hypertension, and hypercholesterolemia. Diabetes Care. 2009;32(8):1531-1535.

40. Segerstrom AB, Glans F, Eriksson KF, et al. Impact of exercise intensity and duration on insulin sensitivity in women with T2D. Eur J Intern Med. 2010;21(5):404-408.

41. Madden KM. Continuous vs interval exercise training in hypertensive subjects. Hypertens Res. 2010;33(6):544-545.

42. Cadore EL, Rodríguez-Mañas L, Sinclair A, Izquierdo M. Effects of different exercise interventions on risk of falls, gait ability and balance in physically frail older adults. A systematic review. Rejuvenation Res. 2013;16(2):105-114.

43. Hu G, Lakka TA, Kilpeläinen TO, Tuomilehto J. Epidemiological studies of exercise in diabetes prevention. Appl Physiol Nutr Metab. 2007;32(3):583-595.

44. Gibala MJ, Little JP, Macdonald MJ, Hawley JA. Physiological adaptations to low-volume, high-intensity interval training in health and disease. J Physiol. 2012;590(Pt 5):1077-1084.

45. Puigserver P, Spiegelman BM. Peroxisome proliferator-activated receptor-gamma coactivator 1 alpha (PGC-1 alpha): transcriptional coactivator and metabolic regulator. Endocr Rev. 2003;24(1): 78-90.
46. Little JP, Safdar A, Bishop D, Tarnopolsky MA, Gibala MJ. An acute bout of high-intensity interval training increases the nuclear abundance of PGC1alpha and activates mitochondrial biogenesis in human skeletal muscle. Am J Physiol Regul Integr Comp Physiol. 2011;300(6):R1303-R1310.

47. Gillen JB, Little JP, Punthakee Z, Tarnopolsky MA, Riddell MC, Gibala MJ. Acute high-intensity interval exercise reduces the postprandial glucose response and prevalence of hyperglycaemia in patients with type 2 diabetes. Diabetes Obes Metab. 2012;14(6):575-577.

48. Sukala WR, Page R, Cheema BS. Exercise training in high-risk ethnic populations with type 2 diabetes: a systematic review of clinical trials Diabetes Res Clin Pract. 2012;97(2):206-216.

49. Glans F, Eriksson KF, Segerström A, Thorsson O, Wollmer P, Groop L. Evaluation of the effects of exercise on insulin sensitivity in Arabian and Swedish women with type 2 diabetes. Diabetes Res Clin Pract. 2009;85(1):69-74.

50. Sukala WR, Page R, Rowlands DS, et al. South Pacific Islanders resist type 2 diabetes: comparison of aerobic and resistance training. Eur $J$ Appl Physiol. 2012;112(1):317-325.

51. Castaneda C, Layne JE, Munoz-Orians L, et al. A randomized controlled trial of resistance exercise training to improve glycemic control in older adults with type 2 diabetes. Diabetes Care. 2002;25(12):2335-2341.

52. Ford ES. Risks for all-cause mortality, cardiovascular disease, and diabetes associated with the metabolic syndrome: a summary of the evidence. Diabetes Care. 2005;28(7):1769-1778.

53. Alberti KG, Eckel RH, Grundy SM, et al; International Diabetes Federation Task Force on Epidemiology and Prevention; Hational Heart, Lung, and Blood Institute; American Heart Association; World Heart Federation; International Atherosclerosis Society; International Association for the Study of Obesity. Harmonizing the metabolic syndrome: a joint interim statement of the International Diabetes Federation Task Force on Epidemiology and Prevention; National Heart, Lung, and Blood Institute; American Heart Association; World Heart Federation; International Atherosclerosis Society; and International Association for the Study of Obesity. Circulation. 2009;120(16):1640-1645.

54. Edwardson CL, Gorely T, Davies MJ, et al. Association of sedentary behaviour with metabolic syndrome: a meta-analysis. PLoS One. 2012;7(4):e34916.

55. Ilanne-Parikka P, Laaksonen DE, Eriksson JG, et al; Finnish Diabetes Prevention Study Group. Leisure-time physical activity and the metabolic syndrome in the Finnish diabetes prevention study. Diabetes Care. 2010;33(7):1610-1617.

56. McAuley KA, Williams SM, Mann JI, et al. Intensive lifestyle changes are necessary to improve insulin sensitivity: a randomized controlled trial. Diabetes Care. 2002;25(3):445-452.

57. Strasser B, Siebert U, Schobersberger W. Resistance training in the treatment of the metabolic syndrome: a systematic review and metaanalysis of the effect of resistance training on metabolic clustering in patients with abnormal glucose metabolism. Sports Med. 2010;40(5): $397-415$.

58. Katzmarzyk PT, Leon AS, Wilmore JH, et al. Targeting the metabolic syndrome with exercise: evidence from the HERITAGE Family Study. Med Sci Sports Exerc. 2003;35(10):1703-1709.

59. Jurca R, Lamonte MJ, Barlow CE, Kampert JB, Church TS, Blair SN. Association of muscular strength with incidence of metabolic syndrome in men. Med Sci Sports Exerc. 2005;37(11):1849-1855.

Diabetes, Metabolic Syndrome and Obesity: Targets and Therapy

\section{Publish your work in this journal}

Diabetes, Metabolic Syndrome and Obesity: Targets and Therapy is an international, peer-reviewed open-access journal committed to the rapid publication of the latest laboratory and clinical findings in the fields of diabetes, metabolic syndrome and obesity research Original research, review, case reports, hypothesis formation, expert opinion and commentaries are all considered for publication. The manuscript management system is completely online and includes a very quick and fair peer-review system, which is all easy to use. Visit http://www.dovepress.com/testimonials.php to read real quotes from published authors. 